\title{
Early Intervention Services for Special Needs Children: An Exploration of the Effectiveness of Early Special Education in Malaysia
}

\author{
Elaine Hui Fern Tan ${ }^{1}$, Zhooriyati Sebu Mohamad \\ ${ }^{1,2}$ Department of Psychology, Faculty of Social Sciences and Liberal Arts, UCSI University \\ Kuala Lumpur (South Wing), No 1, Jalan Menara Gading, UCSI Heights, Taman Connaught, \\ 56000 Cheras, Kuala Lumpur, Malaysia. \\ elainelo196@gmail.com²,zhooriyati@ucsiuniversity.edu.my²; yati_2386@yahoo.com²
}

\begin{abstract}
Early intervention programme (EIP) are a range of different programmes included different types of therapy and education that aimed to help and support children with developmental delays or other specific health conditions. The programmes are helpful to improve children development and adaptability, enhance family capability in handling the special needs children and increase family and children participation in society. This research aims to discover the effectiveness and importance of the early special education in Malaysia. To meet the objectives of this study, a qualitative research using phenomenological approach has conducted on five special needs teachers who work in a Non-Governmental Organization (NGO) early intervention centre in Johor, Malaysia by using purposive sampling. Thematic analysis was used to analyse the collected data. This research found that improvement in attention and behaviours, self-care skills, social interaction skills of special needs children are the effectiveness of early intervention services. Besides that, providing knowledge and happiness to the parents and preparing for integration into kindergarten and future schooling are also some of the effectiveness. The implications of this study consist of contributing significantly to the community by making people understand the effectiveness and importance of sending special needs children to the EIP. It is important for the parents to realise the importance of sending their special needs children to the EIP as earlier as possible as learning occur effective before six years old and behavior more likely to be trained.
\end{abstract}

Keywords: early intervention services, early special education, special needs children

\section{Introduction}

According to Wang (as cited in United Nations Children's Fund, 2014), "We are all born with equal rights. Regardless of our disabilities, we still have the right to be loved, to start our own family, to have access to good education and live a normal healthy lifestyle." Children with disabilities are deserved to be given the chance to grow, develop and enchanted. With the therapy, education, supports, encouragement and love from people around them they have the potential and possibilities to improve, develop and shine bright in their future (United Nations Children's Fund, 2014).

Early intervention services are a range of different programmes that specially planned to

help and support those children with developmental delays or any other specific health condition (World Health Organizations, 2012). The child who undergone early intervention treatment showed improvement in the self-care skills which help them to be independent in the future as the therapists apply natural settings and daily activities to train the kids (Sridevi \& Arya, 2014). One of the common changes that can be seen on any children after joined the early intervention 
program is they will able to dress independently with minimal help from their parent and their attention span will improve as well (Schaaf, Hunt, \& Benevides (2012). However, there are many scientific studies reported that such programmes showed positive feedbacks on the children in different perspectives. For example, the speech therapy helps the autistic children to understand and follow instructions after went through the treatment (Batool \& Ijaz, 2015). There is improvement in the motor skills, sensory processing, communication and interaction skills of the autistic kid through the occupational therapy as the kid will able to socialise and play well with other children in school (Schaaf, Hunt, \& Benevides, 2012). Besides that, the beads technique and colouring method used to train the child attention span also showed the improvements in the children's attention span (Sridevi \& Arya, 2014).

In addition, the speech therapy services also reported can improve the interpersonal skills, psychological well-being of the children after going through the intervention (Roulstone et al., 2012). According to Engle et al (as cited in World Health Organization, 2012), the early intervention programmes could enhance the children's development and make them able to follow well and be effective in the future schooling. This is supported by Wright and Nueman (as cited in Zucker 2010) that in preschool, special needs children need to learn vocabulary which would be useful when they enter primary and secondary school as they would learn more complex concept. However, besides the language, the special needs children also need to learn Mathematics; thus, the teachers could teach them to name the shapes, name the word to describe weight, height, time and distance. Academic problem and development in oral language would happen if the children have limited vocabulary.

The families who attended the early intervention services shown positive results as well (Raspa, Bailey, Olmsted, Nelson, Robinson, Simpson, Guillen, \& Houts, 2010). For instance, Sridevi and Arya (2014) found out that the early intervention programs affects a mother with an autistic kid as well. From the study, it has explained that it is helpful for a mother in handling the child when the parental counselling is provided by giving detailed information and knowledge about the disorder and ways to deal the child is given. It is clear that the families usually will be exposed to the knowledge and abilities in handling their children by attending this program and they will be able to practice the knowledge at their home.

In the Malaysia context, the actual numbers of the children with disabilities is still unavailable (Singh, 2008). According to the Department of Statistics Malaysia, there were around 445,006 people fall into the disabilities category in 2012. However, the exact figure of the children with disabilities still could not be identified among these people (UNICEF, 2014). It is understood that until 2013 only 1\% of the disabled children managed to sign up to the public's special education system (Ministry of Education Malaysia, 2013). From the percentage itself, we could imagine that probably the rest of the $99 \%$ of the special needs children were just staying at home and did not receive any chance of education. According to the Malaysia Education Blueprint 2013-2025, it stated that equal chances of access to the international quality education obliged to everyone (Ministry of Education Malaysia, 2013).

However, in Malaysia there were issues of lack of competency of the special needs educators. Insufficient knowledge, expertise, experiences and training in the early intervention programmes are reported as the barriers in this program (Bari, Abdullah, Abdullah, \& Yasin, 2016; Nasir \& Efendi, 2016). Other than that, there were also challenges of the shortage of speech-language therapist in Malaysia. Sadly, Malaysia is severally low in qualified occupational therapists as there were only 1,395 occupational therapists among the 32 million population. This figure was low as compared to the world ratio which then affect Malaysian to receive good quality services and therapy participation (Loh, Boniface, Mackenzie, \& Richards, 2017). Malaysia is one of the country 
who has no enough speech therapists due to the insufficient local teaching faculty, low interests of the students to register for this degree program and lack of encouragement and supports from the families to study this program (Ahmad, Ibrahim, Othman, \& Vong, 2013).

Besides the lack of manpower, Malaysia also having problem of insufficient facilities of special education. Malaysia is reported has no enough teaching equipment for the special educators (Bari, Abdullah, Abdullah, \& Yasin, 2016) and the special needs educators facing shortage of teaching materials in the classrooms (Nasir \& Efendi, 2016) to conduct the lessons. Above all that, the special educators claimed that due to the limitation of the financial support, it caused them some difficulties to afford the high cost teaching materials which were required for the inclusive education for special needs children (Hussin, Quek, \& Loh, 2008).

The lack in providing a proper education to the special needs children is considered as one of the major issue to be considered. There were parents with learning disabilities children expressed their financial stress that the cost to raise up a special needs child was three times higher than a normal child. Although the government provide financial supports, it is not enough for them to provide quality therapy to their children. Sadly, some of the parents could not afford a car which make them very difficult to bring their children to the therapy (Sukeri, Bakar, Othman, \& Ibrahim, 2017).

Early childhood is the most crucial period for the children to master, learn and adopt skills (Singh, 2013). According to the Center on the Developing Child at Harvard University (2010), they found that the neural circuits, which form the fundamental for learning, behavior and health are most flexible from birth to three years old. With the time pass, it become very hard to transform. The earlier the children get detected and accessed to the early intervention services, the better is it as it could help inhibit any further impairment in the special needs children
(Mensah \& Shayar, 2016). According to UNESCO (2009), there would be challenge when these children enter primary school if they have no receive any early intervention services before as the students would be lack of capacity to benefit from education.

Based on the discussion above, it is understood that having complete and productive teaching materials, equipment, basic amenities are very crucial in influencing the outcome on the children's learning, improvement and growth. Therefore, it is important to have good facilities provide to the children so that they could access to effective lesson. As stated above, due to the limited financial supports it caused some parents incapable to enrol their children in the early intervention services. If the parents with special needs children are provided with financial supports, it would increase the possibilities for them to send their children to the early intervention services. Therefore, this study aims to explore the effectiveness and importance of early intervention services (early special education).

\section{Methodology}

This research was conducted by using a qualitative method with phenomenological approach. This approach was employed since it aimed to describe, decode, translate and derived meaning from the data in order to understand the phenomena of the world. Total five special needs educators from a NonGovernmental Organization (NGO) early intervention center in Johor were recruited by using purposive sampling technique.

A set of predetermined semi-structured interview questions were used to obtain data from the participants. The interview questions were adapted from Moore (2012), Coyle (2011) and Kiyuba and Tukur (2014) research. Besides that, field notes also were taken as well in order to ensure the participants have given sufficient information that are needed for the study.

The results obtained were analysed by using thematic analysis. After data collection process, the data collected were transcribed, 
analysed and interpreted. The significant statements were identified from the transcripts such as effectiveness of early intervention services (early special education). From the significant statements, the coding process that consists of open coding, axial coding and selective coding were then carried out by identifying any words or phrases that are relevant to the research questions. From there, those patterns were reduced into different themes or concepts. The themes were reviewed in order to ensure the themes fit the data (Maguire \& Delahunt, 2017).

\section{Findings and Discussion}

Findings

This research aims to investigate the effectiveness and importance of early special education for the special needs children. The results of this research will be reported in this section.

\section{Effectiveness of early special education}

There was several effectiveness of the early special education discovered from this study which are providing knowledge and happiness to the parents, improvement in attention, behaviors, self-care skills and social interaction skills in the children. The other effectiveness consists of help prepare for integrating into kindergarten and future schooling. Other than that, the importance for sending special needs children to the early intervention program (EIP) at the early age also detected in this study.

\section{Providing knowledge and happiness to the parents}

The study found out that parents have gained various benefits after sending their children to the EIP. For example, the parents are claimed that they learnt knowledge and skills to handle their children. Besides that, they also learnt the suitable methods to teach their children at home from the teachers in EIP. The outcome by attending the EIP shows that the parents felt happier when they noticed positive changes in their children and embrace from the center.
For instance:

'The parents tell us at first they really don't know what to do with their children, they don't see hope, but everything changes after they send their children here. Now they know how to deal with their child's behaviors and how to teach them in academic learning."

\section{Improvement in attention and behaviors}

Based on the results obtained in this study, it has proven that there is various positive improvement in the behaviors and attention span of the children after they enrolled in the center. This is because the center designed some activities that could train their attention span. Basically, most of the activities in the center focus on training their hand-eye coordination and eye focus. For instance, drawing a straight line or lazing which required the children to pay much attention in order to complete the tasks. The activities provided in the EIP also helps the children to sit still, listen and follow instructions.

For example:

"There are many students who cannot sit still and listen to the teachers at first, but after they come to our center for a certain period, they are able to sit quietly, listen to the teachers and able to understand and follow instructions. The children's attention span improves as well as most of our activities here focus on training their band-eye coordination and eye focus."

\section{Improvement in self-care skills}

The results show that the center has designed different types of activities to train the children to be independent. For instance, the center encourages some children to attend the EIP without accompanied by their parents. The outcome of this method is the children were able to be independent after attended to the center for a while. The children show their independency through wearing shoes, going toilet and taking care of own personal belongings.

For instance: 


\section{Early intervention services for special needs children ... Elaine Tan Hui Fern ${ }^{1}$, \& Zhooriyati, S. M. ${ }^{2}$}

"Lazing and beading activities enables the children to learn to tie their shoes lace, button their own shirts in the future so that they do not need to rely fully on their parents in getting dressed."

"Some of them at first they are not able to go to toilet by themselves, now they will go by their own without the reminder of the teachers, they are able to put on and off their pants, their self-help skills improved a lot, they know where it's their place to put their school bags and belongings everytime when they come and will remember to bring back their belongings, wear and take off their shoes by themselves, they have really become more independent compared to the beginning."

Improvement in social-interaction skills

Above all, the children also show interaction with other people such as friends and teachers after enrolled in the center. One of the biggest positive impact after joined the EIP is the children are able to recognize other peoples' name and response to them. Besides that, these children also become happier. In addition, these changes help the children to engage in group activities and some even develop friendship in the center.

For example:

"For social interaction skills, I would say it did improve because when the children come here they got the chance to interact and social with other people such as the teachers and also their classmates. Sometimes you could see some children play together and even chat with each other. There are parents told me that their children become happier after coming to our center."

"I realized that the children at first when they come, they were very quiet, and some would even cry refuse to stay, but after come to the center for several months, they will response to you when you greet them for example 'Good Morning' even though they speak it in a very soft voice, but it is enough for us."

Preparing for integration into kindergarten and future schooling

The research found that the teaching method applied in EIP and the syllabus are helpful because it prepares the children for future schooling. As most of the children are visual learners, the center applies private or one to one teaching method and use word sheets and flash cards to help them to learn. The center teaches by starting from basic level then only move on into next level which includes teaching language (Malay, English), alphabet, recognize objects and recognize numbers. Some children started to talk slowly after enrolled to the center as the teachers let the children watch their mouth in order to produce sound. However, Makaton sign language is used to teach down syndrome to communicate.

For instance:

"We will teach language especially Malay language as we used BM (Malay language) as our teaching instructions. Besides that, we also teach some very simple and basic English terms. In terms of language, we will teach them alphabet like $A$ to $Z$, and we also teach them to recognize and name the body parts and objects. we also teach them numbers like recognize and name 1, 2, 3, 4."

"When they can recognize the alphabets only we move on to teach them vocabulary. These children they mostly are visual learners, so when we are teaching them the vocabulary we will used flash cards with colourful pictures to grab their attention and stimulate their motivation as well."

\section{Importance to receive EIP at early age}

The participants claimed that children's behavior are more likely to be handle if they attend the EIP earlier. They reported that significant improvement could be seen as they learn and absorb information and knowledge faster during the first six years. Child behavior and thinking more likely to change if detected earlier, otherwise the bad behaviors will become the habit and then hard to change. It can be concluded that the learning occurs effective at early age and the critical period for learning are before six years old. There will be some difficulties if miss this period learning.

For example:

"If we managed to detect the children condition earlier, then it would contribute much to the children 
developmental growth. If detected late, certain things would become difficult to fix and change. For example, bad behaviors as it would become a habit and then become hard to modified. Their thinking also if become fixed, it would also very hard to modify as well."

\section{Discussion}

As discussed earlier, there are several effectiveness of early special education. For example, the EIP is important in providing knowledge and happiness to the parents, improvement in attention and behaviors, improvement in self-care skills, improvement in social-interaction skills, preparing for integrating into kindergarten and future schooling.

One of the effectiveness of EIP is to provide parents with the knowledge and skills in teaching and handling children. This result is similar to the previous study by Sridevi and Arya (2014) where they found out that the participants were able to handle their children at home after received the detailed information and knowledge about the autism. Besides that, it was helpful for the parents when they observe the correct methods to deal with their children. In the current study, most parents reported that at first, they have no clue in handling their children. However, after they accompany their children to the EIP center, they started to learn and apply knowledge and skills to teach their children in home by observing how the teachers teach their children. Another study done by Raspa and his colleagues in 2010 described that parent's participation in EIP make them become more confident in their ability in taking care their children with developmental delay (Raspa et al., 2010). From these findings, it is obvious that EIP teach parents on how to handle their special needs children. It is understood that the EIP is not helpful for the children only, but the parents as they could gain various benefits as well. As we discussed earlier, the method used by the parents or the caretakers are important for the child development. Therefore, the activities provided in the EIP program is very helpful in educating the parents as they can apply the methods in their home since the children spent more time at home compared to the centre.

Improvement in attention and behaviors of special needs children also another effectiveness of EIP discovered from this study. The children are able to understand, follow instructions, sit still and concentrate during lesson after enrolled to EIP for a while. This is because the center prepared activities that train their attention span such as beadings, drawing a straight lines and others. This finding is consistent with the study by Sridevi and Arya (2014) where they discovered the attention span of that child improved after attend the intervention as he was able to sit still for 30 minutes together with the therapists. In that study, the psychologists used beads technique and colouring method to train his attention and concentration (Sridevi \& Arya, 2014). Besides that, the results of current study have similarity with a study by Batool and Ijaz (2015) where they discovered that the children managed to understand and follow instructions after went through the treatment. According to these findings, it shows EIP help train children attention and behaviors. Improvement in the attention and behaviors of the special needs children could have significant difference to their future studies when they enter primary school as they are expected able to sit still, listen to instructions and pay attention during the lesson.

Improvement in the self-care skills of the special needs children is another effectiveness of attending EIP. After the children attended the EIP, they became more independent and able to do many things independently such as dressing, wearing shoes, eating, going to toilet and taking care of own personal belongings. This result is consistent with the previous study by Schaaf and his colleagues where they discovered that children who receive occupational therapy were able to dress independently with minimal help from his parent (Schaaf, Hunt, \& Benevides, 2012). The current study also shows that the EIP teachers design activities and situations to train children become more independent. For example, the teachers encourage the students to go to the center alone to train their 
independence. This finding show consistency with the previous study where Sridevi and Arya (2014) mentioned that during the treatment, the therapists or psychologists applied natural settings of daily activities to train the autistic kid to be more independent. Therefore, parents are very encouraging to send their children to the EIP so that these children could learn to be more independent in the future. These children should learn how to be independent since young so that they could be function well when they grow up such as getting a job, living alone and others. Parents should realize that they are impossible to take care of their children forever, therefore it is important for the children to learn how to be independent.

Another effectiveness of EIP discovered from this study is improvement in social interaction skills of the special needs children. From this study it was mentioned that those children would interact, play with the teachers and the other children in the center after come to the center for a short period of time. In addition, some of the children would be able to response verbally to the teachers by greeting the teachers. It shown that they started to response to the surroundings and the EIP teachers also felt that these children become happier after come to the center. Similar results have been discovered in the previous studies where it is stated that there was improvement in interpersonal skills, psychological well-being of the children after going through the speech therapy (Roulstone et al., 2012). In addition, in another study done by Schaaf and his colleagues noted that sensory integration intervention enhance the interaction skills of the autistic kid as that participant was able to social and play well with other children in school (Schaaf, Hunt, \& Benevides, 2012). Another case study done by Ciucurel and Iconaru (2012) on a down syndrome kid shown that the kid show improvement in interaction skills after gone through occupational therapy as he was able to take part in football with the team and interact with others in school (Ciucurel \& Iconaru, 2012). As discussed earlier, EIP helps improve the social interaction skills of the special needs children. By going to the center, the children would able to interact with people other than their family members and they would able to learn how to social with people. Other than that, it makes them able to learn to adapt to the society rather than just staying at home.

Another effectiveness of EIP discovered from this research is to help prepare for integrating into kindergarten and future schooling. This current study reported that the syllabus used help the children adapt and prepare for future schooling. The children in the center learnt alphabets, vocabulary, basic numbers, recognize objects and others. This result is supported with the study by Wright and Nueman (as cited in Zucker 2010) that in preschool special needs children need to learn vocabulary which would be useful when they enter primary and secondary school as they would learn more complex concept. Academic problem and development in oral language would be happen if the children with limited vocabulary. They also need to learn Mathematics; thus, the teachers could teach them to name the shapes, name the word to describe weight, height, time and distance (Zucker, 2010). The result obtained from this research also show consistency with another study done by Sridevi and Arya (2014) where the participant in the study who had gone through intervention had receive pre-academic skill training. During the training, the participant would learn basic concept such as alphabets, numbers, size, colours and others. Another study by Engle et al (as cited in World Health Organization, 2012) revealed that the early intervention programmes could enhance the children's development and make them able to follow well and effective in future schooling. Preparing for future schooling also found in another study. The study shown that early special education prepares the children in academic way before they enter primary school, hence it prepares them for future school performance and learning (Mensah \& Badu-Shayar, 2016). In addition, the findings from UNESCO (2009) claimed that there would be challenge when these children enter primary school if they have no receive any early intervention services before as the students 
would be lack of capacity to benefit from education (UNESCO, 2009). As discussed above, it shows that EIP help prepare the children in the academic way thus it makes them able to follow well in the future schooling and makes them able to face more difficult syllabus in the future.

\section{Conclusion and Recommendations}

Conclusion

In conclusion, there are many effectiveness of sending special needs children to the early intervention services (early special education) found in this study. It is important for the parents to realise and aware of how important it is to send their special needs children to the EIP as earlier as possible as learning occur effective before six years old and behavior more likely to be trained. Once they miss this critical period it would be very difficult for them to improve and develop. However, there are many challenges faced by the EIP teachers which prevent them to provide the best intervention to these children. Therefore, the government and public should implement actions to help and improve the intervention in Malaysia, so that these children could get helped and improved.

The findings of this research provide insights for the community by making people understand the effectiveness and importance of sending special needs children to the EIP. By doing this research it could raise the awareness and commitment of the government or other related bodies to channel funds or grants into the early intervention service. By having the financial supports it could improve the facilities of the special education system that we have in Malaysia, so that the special needs children could be receiving the highest professional and effective services.

\section{Recommendations}

It is suggested that the future researcher could examine the perceptions of the EIP teachers in both private and NGO sector and then do comparison on the study so that the differences and similarities of their perceptions could be investigated. Besides that, the future researcher could recruit the EIP teachers who work in the NGO settings all around Malaysia instead of just one area, so that the results collected would have greater generalizability. In this research, all the participants involved have different years of experiences and education background it might influence their perceptions on this field, therefore the future researcher could probably only recruit teachers with certain years of experiences and certain educational background. Also, the future researchers could focus on the perceptions of the therapists in this field such as occupational therapists, speech therapists or others.

\section{References}

Ahmad, K., Ibrahim, H., Othman, B. F., \& Vong, E. (2013). Addressing education of speech-language pathologists in the World Report on Disability: Development of a speech-language pathology program in Malaysia. International Journal of Speech-Language Pathology, 15(1), 37-41. doi: 10.3109/17549507.2012.757709

Bari, S., Abdullah, N. A., Abdullah, N., \& Yasin, M. H. M. (2016). Early intervention implementation preschool special education students in Malaysia. International Journal for Innovation Education and Research, 4(6), 139-155.

Batool, I., \& Ijaz, A. (2015). Effectiveness of speech and language therapy for autism spectrum disorder. Journal of Pakistan Psychiatric Society, 12(1), 14-17.

Center on the Developing Child at Harvard University. (2010). The Foundations of Lifelong Health Are Built in Early Childhood. Retrieved from http://developingchild.harvard.edu/wp

content/uploads/2010/05/Foundation s-of-Lifelong-Health.pdf

Coyle, S. (2011). A qualitative analysis: "The effect of Music Therapy on a person with intellectual disability" (Master's Thesis). Retrieved from 
https://esource.dbs.ie/handle/10788/3 12

Hussin, S., Quek, A.H., \& Loh, S. C. (2008). Policy into Practice: The Challenge for Special Education in Malaysia. Retrieved from

http://eprints.um.edu.my/10347/1/10 6 Paper.pdf

Kiyuba, J., \& Tukur, S.Y. (2014). Challenges Of Providing Special Education To Children With Disabilities View of teachers and education officials (Degree's Thesis). Retrieved from http://www.diva-

portal.org/smash/get/diva2:764634/F ULLTEXT01.pdf

Loh, S. Y., Boniface, G., Mackenzie, L., \& Richards, L. (2017). Professional autonomy and progress of occupational therapy - A case study on a neglected health profession in Malaysia. Journal of Hospital and Healthcare Administration, 2017(1), 1-6. doi:10.29011/JHHA-105. 100005

Maguire, M., \& Delahunt, B. (2017). Doing a thematic analysis: A practical, step-bystep guide for learning and teaching scholars. The All Ireland Journal of Teaching and Learning in Higher Education, 8(3), 3351-33514.

Mensah, F. A., \& Shayar, J. B. (2016). Identification of special educational needs for early childhood inclusive education in Ghana. Journal of Education and Practice, 7(11), 1-8. Retrieved from https:// files.eric.ed.gov/fulltext/EJ109 9548.pdf

Ministry of Education Malaysia. (2013). Malaysia Education Blueprint 2013 - 2025 (Preschool to Post-Secondary Education). Retrieved from https://www.moe.gov.my/images/dasa r-kpm/articlefile file 003108.pdf

Moore, R. (2012). Defining Support: Families of children with special needs and the role of the speech language pathologist. Ursidae: The Undergraduate Research Journal at the University of Northern Colorado, 2(2), 1-20. Retrieved from https://digscholarship.unco.edu/cgi/vi ewcontent.cgi?article $=1041 \& \operatorname{context}=\mathrm{u}$ rj

Nasir, M. N. A., \& Efendi, A. N. A. E. (2016). Special education for children with disabilities in Malaysia: Progress and obstacles. Malaysian Journal of Society and Space, 12(10), 78-87.

Raspa, M., Bailey, D. B., Jr., Olmsted, M. G., Nelson, R., Robinson, N., Simpson, M. E., Guillen, C., \& Houts, R. (2010) Measuring family outcomes in early intervention: findings from a large-scale assessment. Exceptional Children, 76(4), 496-510.

Roulstone, S., Wren, Y., Bakopoulou, I., \& Lindsay, G. (2012). Interventions for children with speech, language and communication needs: An exploration of current practice. Child Language Teaching and Therapy, 28(3), 325-341. doi: $10.1177 / 0265659012456385$

Schaaf, R. C., Hunt, J., \& Benevides, T. W. (2012). Occupational therapy using sensory integration to improve participation of a child with autism: A case report. The American Journal of Occupational Therapy, 66(5), 1-9. doi :10.5014/ajot.2012.004473

Schaaf, R. C., Hunt, J., \& Benevides, T. W. (2012). Occupational therapy using sensory integration to improve participation of a child with autism: A case report. The American Journal of Occupational Therapy, 66(5), 1-9. doi :10.5014/ajot.2012.004473

Singh, A. (2008). Meeting the needs of children with disability in malaysia. the medical journal of Malaysia, 63(1), 1-3. Retrieved from https://www.researchgate.net/publicati on/23399309

Singh, A. (2013). Screening \& Diagnosing Learning Disabilities. Forum on the Right of Education for Children with Learning Disabilities, Human Rights Commission of Malaysia (SUHAKAM). Retrieved from www.necicmalaysia.org/view_file.cfm?fi leid $=95$

Sridevi, G., \& Arya, S. (2014). Effect of early intervention in autism: A case study. 
International Journal of Scientific and Research Publications, 4(4), 2250-3153.

Sukeri, S., Bakar, R. S., Othman, A., \& Ibrahim, M. I. (2017). Barriers to unmet needs among mothers of children with disabilities in Kelantan, Malaysia: A qualitative study. Journal of Taibah University Medical Sciences, 12(5), 424-429. doi: 10.1016/j.jtumed.2017.05.002

United Nations Children's Fund. (2014). Children with Disabilities in Malaysia. Retrieved from https://www.unicef.org/malaysia/UNI CEF-

Children_with_Disability_in_Malaysia_ 2014_lowres.pdf

United Nations Educational, Scientific and Cultural Organization. (2009). Policy Guidelines on Inclusion in Education. Retrieved from http://unesdoc.unesco.org/images/001 7/001778/177849e.pdf

World Health Organization. (2012). Early Childhood Development and Disability:A discussion paper. Retrieved from http://apps.who.int/iris/bitstream/106 65/75355/1/9789241504065 eng.pdf

Zucker, G. H. (2010). Intervention Strategies for Pre-School Students with Special Needs. Forum on Public Policy, 1-11. Retrieved from https:// files.eric.ed.gov/fulltext/EJ912 980.pdf 